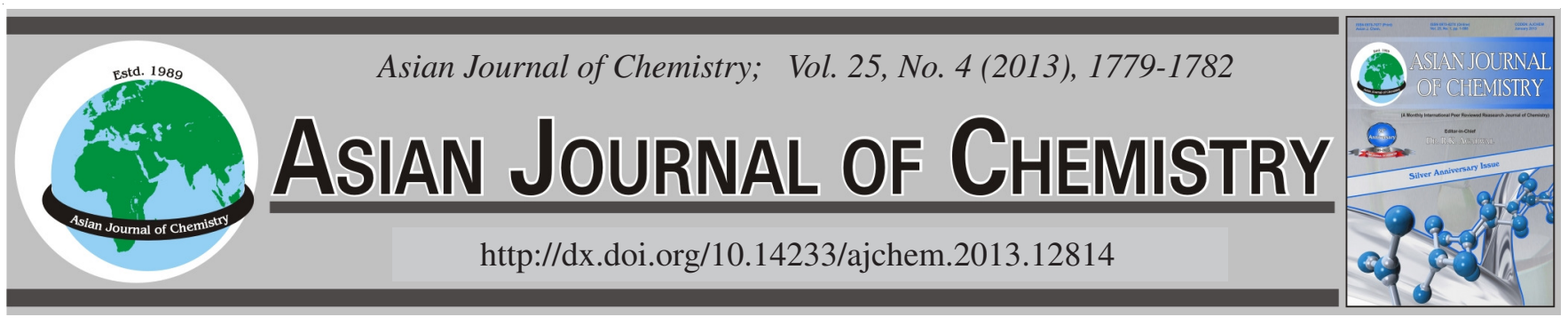

\title{
Determination of Protocatechuic Aldehyde in Danshen Injection by Flow Injection Chemiluminescence
}

\author{
Shihao ZhaO ${ }^{1}$, PingPing Zhang ${ }^{2, *}$ and Jing FenG ${ }^{3}$
}

${ }^{1}$ College of Biology Science and Engineering, Hebei University of Economics and Business, Shijiazhuang 050061, P.R. China ${ }^{2}$ Institute of Basic Medicine, Hebei Medical University, Shijiazhuang 050017, P.R. China

${ }^{3}$ Hebei Chemical and Pharmaceutical Vocational Technology College, Shijjiazhuang 050031, P.R. China

*Corresponding author: E-mail: jumping.zpp@yeah.net

\begin{abstract}
A novel chemiluminescence system for determination of protocatechuic aldehyde with flow injection analysis is described. It is based on the chemiluminescence reaction of potassium ferricyanide and luminol in sodium hydroxide medium. The optimized experimental conditions were evaluated. Under optimum conditions, calibration curve over the range of 1.0-50 mg L $\mathrm{m}^{-1}$ was obtained $(\mathrm{r}=0.9992)$. The detection limit of this method was $0.2 \mathrm{mg} \mathrm{L}^{-1}$. The relative standard deviation was $3.4 \%$ for $20 \mathrm{mg} \mathrm{L}^{-1}$ protocatechuic aldehyde. The method has been applied to the determination of studied protocatechuic aldehyde in Danshen injection with a satisfactory result.
\end{abstract}

Key Words: Protocatechuic aldehyde, Potassium ferricyanide, Luminol, Chemiluminescence.

\section{INTRODUCTION}

Danshen injection made from the aqueous extracts of Salvia miltiorrhiza Bunge. It is one of the earliest and also the most commonly used herbal drug in practice of traditional Chinese medicine. It is widely used to treat coronary heart disease, cerebrovascular disease, hepatitis, hepatocirrhosis and chronic renal failure ${ }^{1-3}$. Protocatechuic aldehyde had been considered as one of the major active constituents of Salvia miltiorrhiza. A number of pharmacological studies showed that protocatechuic aldehyde possessed arrays of biological activities as anti-cardium colic, improving microcirculation, reducing atherosclerosis, inhibiting the virus replication, inhibiting the aggregation of platelets etc. ${ }^{4-7}$. There are great interests in the therapeutic potential of protocatechuic aldehyde. Biological properties of protocatechuic aldehyde closely depend on its bioavailability. Therefore, it is important to develop simple, sensitive and accurate methods for being able to detect protocatechuic aldehyde.

Methods of analysis for protocatechuic aldehyde were grouped into thin layer chromatography scanning ${ }^{8}$, capillary electrophoresis ${ }^{9}$, infrared spectrophotometric ${ }^{10}$ and high performance liquid chromatography (HPLC) $)^{11,12}$ method. Although thin layer chromatography scanning is the most commonly used method but it is time consuming, needs great care and skill. The detection limit of infrared spectrophotometric can not meet the requirement of lower concentration. Capillary electrophoresis and HPLC had the advantage of separating and quantifying of protocatechuic aldehyde, but involve set up cost, a complex extraction, and purification procedure. Chemiluminescence is a powerful analytical technique that has excellent sensitivity, wide linear dynamic range and requires relatively simple and inexpensive instrumentation. However there were few reports for the determination of protocatechuic aldehyde based on chemiluminescence analysis system.

In this study, we found that a strong chemiluminescence signal was given out when a trace amount of protocatechuic aldehyde was added to potassium ferricyanide and luminol mixed solution and the chemiluminescence intensity was strongly dependent on protocatechuic aldehyde concentration. Based on this phenomenon, a new, rapid, simple, sensitive and inexpensive method is proposed to determine protocatechuic aldehyde in Danshen injection. It has more widely linear range and much lower detection limit. The method has been applied to the determination of studied protocatechuic aldehyde in Danshen injection with a satisfactory result.

\section{EXPERIMENTAL}

$\mathrm{K}_{3}\left[\mathrm{Fe}(\mathrm{CN})_{6}\right]$ protocatechuic aldehyde were obtained from Beijing Chemical Reagent Company (Beijing, China), luminol was obtained from Sigma-Aldrich (St. Louis, Mo, USA), $\mathrm{NaOH}$ was obtained from Tianjin Chemical Reagent Company (Tianjin, China). A luminol stock solution $\left(0.01 \mathrm{~mol} \mathrm{~L}^{-1}\right)$ was prepared by dissolving $0.443 \mathrm{~g}$ luminol in $5.0 \mathrm{~mL}$ of $1 \mathrm{~mol} \mathrm{~L}^{-1}$ $\mathrm{NaOH}$ and then transferring the solution into a $250 \mathrm{~mL}$ volumetric flask and diluting with water. A protocatechuic aldehyde 
stock solution $\left(0.1 \mathrm{~g} \mathrm{~L}^{-1}\right)$ was prepared by dissolving $1 \mathrm{mg}$ protocatechuic aldehyde in $10 \mathrm{~mL}$ water. $\mathrm{A} \mathrm{K}_{3} \mathrm{Fe}(\mathrm{CN})_{6}$ stock solution $\left(5.0 \times 10^{-3} \mathrm{~mol} \mathrm{~L}^{-1}\right)$ was prepared by dissolving 1.646 $\mathrm{g}$ protocatechuic aldehyde in $1 \mathrm{~L}$ water. Borax, phosphate, acetic acid, and sodium acetate were obtained either from Beijing Chemical Reagent Company (Beijing, China) or from Tianjin Chemical Reagent Company (Tianjin, China). All the above reagents were of analytical grade and used as received without further purification. Double-distilled water (referred to pure water hereafter) was used as carrier and for the preparation of solutions. The diluted working solutions were prepared and used freshly and daily.

Flow injection chemiluminescence was performed with an IFFL-D flow injection chemiluminescence analysis system (Xi'an Ruike Electronic Equipment Corporate, Xi'an, China). The schematic diagram of the FI-CL analyzer is shown in Fig. 1. It consisted of 2 peristaltic pumps (working at a constant flow rate of $30 \mathrm{rpm}$ ). One channel was used to carry $\mathrm{NaOH}$ and luminol solution, the other channel was used to carry the $\mathrm{K}_{3}\left[\mathrm{Fe}(\mathrm{CN})_{6}\right]$ solution, Sample solutions were then injected from a sample valve. The enhanced chemiluminescence signals were produced immediately and were recorded. The flow cell was a $10-\mathrm{cm}$ long spiral glass tubing $(2.0 \mathrm{~mm}$ i.d.) and the distance between injection valve and flow cell was about 15 $\mathrm{cm}$. Fluorescence spectra were taken on CRT-970 fluorescence spectrophotometer (Sanco Co., Shanghai, China).

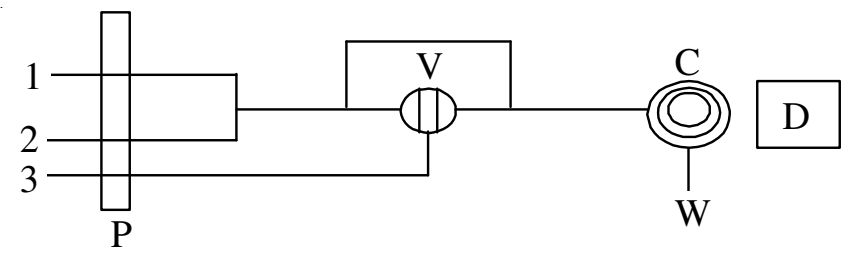

Fig. 1. Schematic of flow injection chemiluminescence analysis; 1. Mixture of $\mathrm{NaOH}$ and luminol; 2. $\mathrm{K}_{3} \mathrm{Fe}(\mathrm{CN})_{6}$ solution; 3. Protocatechuic aldehyde solution; C. Flow cell; V. Injection valve; W. Waste solution; D. Detector

\section{RESULTS AND DISCUSSION}

The kinetic curves of the chemiluminescence reaction were tested with a static system, using $5.0 \times 10^{-5}$ luminol $5.0 \times$ $10^{-6} \mathrm{~mol} \mathrm{~L}^{-1} \mathrm{~K}_{3}\left[\mathrm{Fe}(\mathrm{CN})_{6}\right]$. It was found that the reaction rate in solution was rapid; from reagent mixing to the peak maximum $1 \mathrm{~s}$ was needed and it took about $4 \mathrm{~s}$ for the signal to return to zero again as illustrated in Fig. 2(a). It was also shown that the chemiluminescence intensity increased sharply in the presence of $20 \mathrm{mg} \mathrm{L}^{-1}$ protocatechuic aldehyde as seen in Fig. 2(b).

The chemiluminescence spectra were studied using a SANCO 970CRT spectrofluorophotometer with a flowinjection system with its excitation light output slit set at zero. The chemiluminescence intensities of luminol- $\mathrm{K}_{3} \mathrm{Fe}(\mathrm{CN})_{6}$ and of luminol- protocatechuic aldehyde $-\mathrm{K}_{3} \mathrm{Fe}(\mathrm{CN})_{6}$ were detected, respectively. The maximum chemiluminescence spectra of these 2 kinds of mixed solutions gave one peak at about $425 \mathrm{~nm}$ (Fig. 3), suggesting that all these chemiluminescence reactions shared a common emitting species, the same as the maximum emission spectrum of 3-aminophthalate ions $(3-\mathrm{AP} *)^{13}$, which is a luminol luminescence species. There is no new emitter

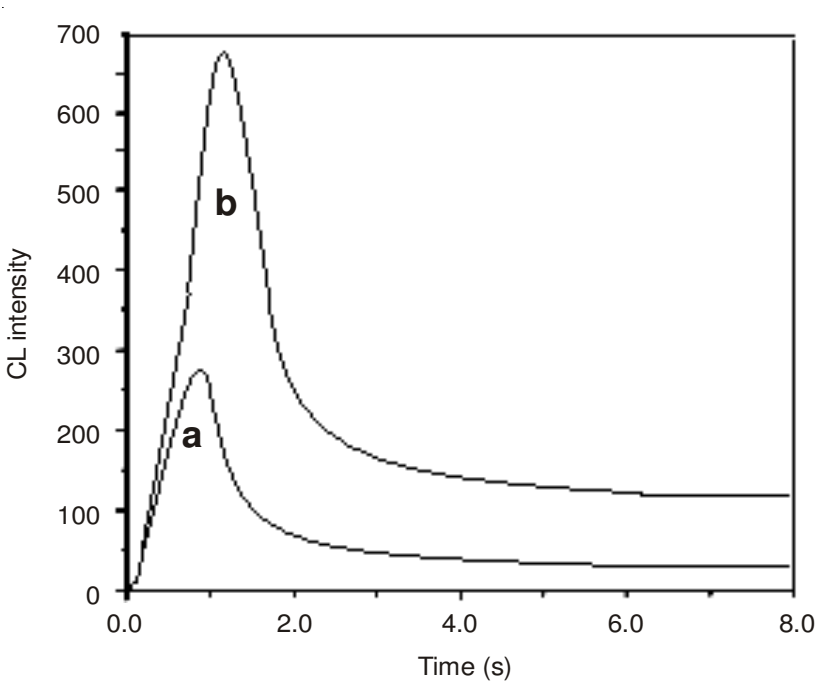

Fig. 2. Chemiluminescence kinetic curve of the chemiluminescence reaction; (a) $5.0 \times 10^{-5}$ luminol $-5.0 \times 10^{-6} \mathrm{~mol} \mathrm{~L}^{-1} \mathrm{~K}_{3}\left[\mathrm{Fe}(\mathrm{CN})_{6}\right]$, (b) $5.0 \times 10^{-5}$ luminol $-5.0 \times 10^{-6} \mathrm{~mol} \mathrm{~L}^{-1} \mathrm{~K}_{3}\left[\mathrm{Fe}(\mathrm{CN})_{6}\right]-20 \mathrm{mg} \mathrm{L}^{-1}$ protocatechuic aldehyde

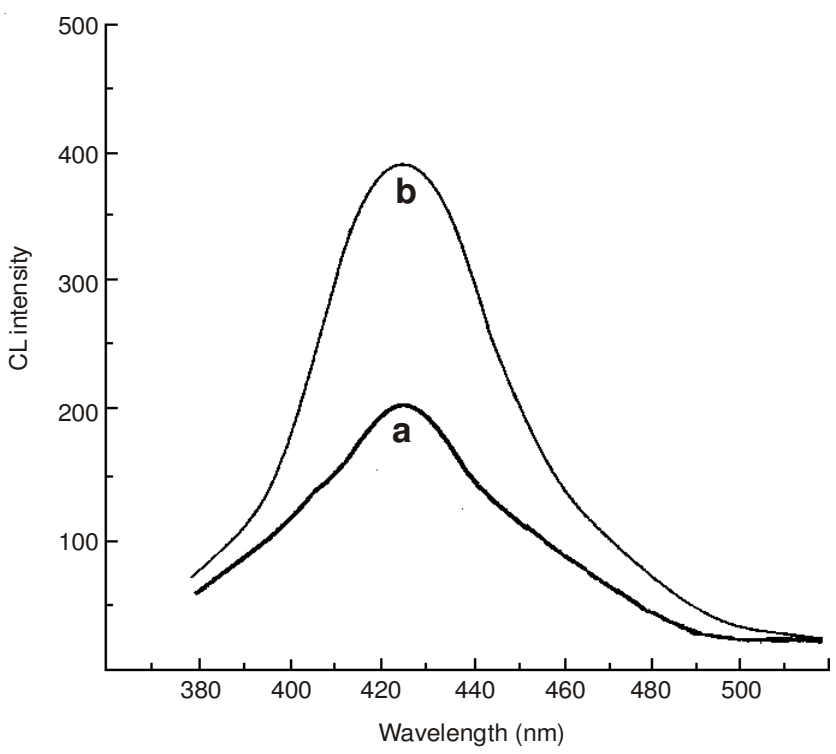

Fig. 3. Chmiluminescence spectra of the system; (a) $5.0 \times 10^{-5}$ luminol $5.0 \times 10^{-6} \mathrm{~mol} \mathrm{~L}^{-1} \mathrm{~K}_{3}\left[\mathrm{Fe}(\mathrm{CN})_{6}\right]$, (b) $5.0 \times 10^{-5}$ luminol $-5.0 \times 10^{-6}$ $\mathrm{mol} \mathrm{L}^{-1} \mathrm{~K}_{3}\left[\mathrm{Fe}(\mathrm{CN})_{6}\right]-20 \mathrm{mg} \mathrm{L}^{-1}$ protocatechuic aldehyde

produced in the reaction, the role of protocatechuic aldehyde was only as an enhancement reagent. Therefore, it was indicated that protocatechuic aldehyde did not change the mechanism of the chemiluminescence reaction.

Effect of flow rate on chemiluminescence intensity: The chemiluminescence intensity increased with increasing the flow rate, but if the flow rate was too slow or too fast, a suitable chemiluminescence intensity could not be obtained. A flow rate of $30 \mathrm{rpm}$ for all solutions seemed to give the best results, which was employed in all the measurements.

Effect of carrier flow: A number of carrier flows were tested at these selection conditions: $\left([\mathrm{PA}]=20 \mathrm{mg} \mathrm{L}^{-1}\right.$, $[$ Luminol $]=5.0 \times 10^{-5} \mathrm{~mol} \mathrm{~L}^{-1} ;\left[\mathrm{K}_{3} \mathrm{Fe}(\mathrm{CN})_{6}\right]=5.0 \times 10^{-6} \mathrm{~mol}$ $\mathrm{L}^{-1}$ ), those flow rates included $\mathrm{NaOH}$, borax, phosphate buffer, and acetic acid- sodium acetate solutions. The experiments indicated that the chemiluminescence emission intensity were 
the most sensitive in $\mathrm{NaOH}$ solution. The influence of $\mathrm{NaOH}$ concentration over the range $0.05-0.5 \mathrm{~mol} \mathrm{~L}^{-1}$ on chemiluminescence emission intensities was investigated further, and to our surprise, the use of $0.2 \mathrm{~mol} \mathrm{~L}^{-1} \mathrm{NaOH}$ solution as a carrier flow gave the best result; thus, we chose $0.2 \mathrm{~mol} \mathrm{~L}^{-1} \mathrm{NaOH}$ solution as the carrier flow.

Effect of concentration of luminol on chemiluminescence intensities: The concentration of luminol used in the reaction was also studied. The chemiluminescence emission intensity was enhanced with the luminol concentration increasing while keeping the alkaline concentration and other reactants constant. It was found that chemiluminescence intensities increased with the increase in luminol concentration (Fig. 4). On the other hand, the base signal of chemiluminescence generated by the reaction between $\mathrm{K}_{3}\left[\mathrm{Fe}(\mathrm{CN})_{6}\right]$ and luminol also increased. In turn, the signal-to-noise ratio $(\mathrm{S} / \mathrm{N})$ increased as well. After an analysis of the $\mathrm{S} / \mathrm{N}$ ratio of the baseline and the sensitivity of the system, the best concentration of luminol was $5.0 \times 10^{-5} \mathrm{~mol} \mathrm{~L}^{-1}$.

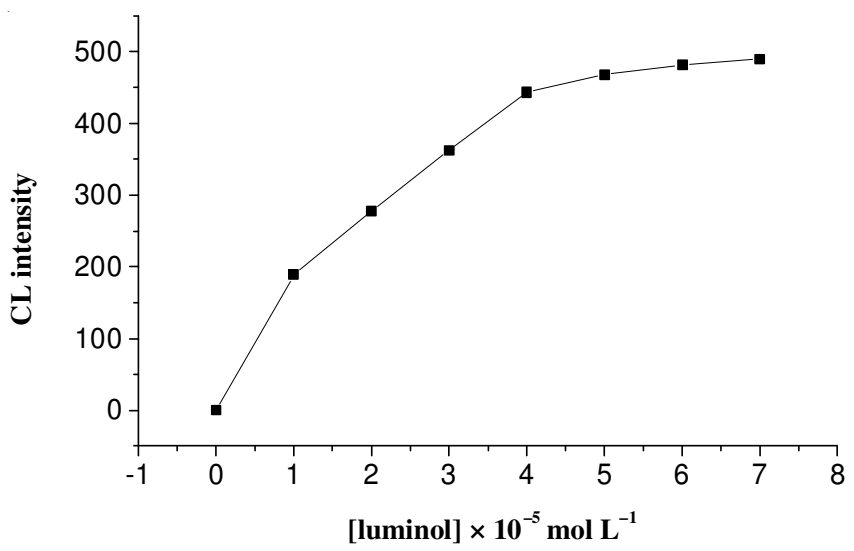

Fig. 4. Effect of luminol concentration on chemiluminescence intensity. Condition: $[\mathrm{PA}]=20 \mathrm{mg} \mathrm{L}^{-1},\left[\mathrm{~K}_{3} \mathrm{Fe}(\mathrm{CN})_{6}\right]=5.0 \times 10^{-6} \mathrm{~mol} \mathrm{~L}^{-1}$, luminol in $0.2 \mathrm{~mol} \mathrm{~L}^{-1} \mathrm{NaOH}$ solution

Effect of $\mathrm{K}_{3}\left[\mathrm{Fe}(\mathrm{CN})_{6}\right]$ concentration on chemiluminescence intensities: Fig. 5 shows the chemiluminescence intensities as a function of $\mathrm{K}_{3}\left[\mathrm{Fe}(\mathrm{CN})_{6}\right]$ while keeping other reactants constant. Obviously, maximum chemiluminescence intensity was obtained when $\mathrm{K}_{3}\left[\mathrm{Fe}(\mathrm{CN})_{6}\right]$ was at $5.0 \times 10^{-6}$ mol L ${ }^{-1}$. Above this concentration, chemiluminescence intensity decreased, may be due to the inner filter effect caused by absorption of the chemiluminescence emission by the high concentration of $\mathrm{K}_{3}\left[\mathrm{Fe}(\mathrm{CN})_{6}\right]$. So the optimum concentration of $\mathrm{K}_{3}\left[\mathrm{Fe}(\mathrm{CN})_{6}\right]$ was therefore chosen as $5 \times 10^{-6} \mathrm{~mol} \mathrm{~L}^{-1}$.

Performance of the system for protocatechuic aldehyde measurements: Under the optimal conditions described above, the linear detection range was from 1.0 to $50 \mathrm{mg} \mathrm{L}^{-1}$, A regression equation was obtained as:

$$
\text { Intensity }=6.727+23.263 \mathrm{c}\left(\mathrm{c}: \mathrm{mg} \mathrm{L}^{-1}, \mathrm{r}=0.9992\right)
$$

The detection limit $(3 \sigma)$ for the regression equation was $0.2 \mathrm{mg} \mathrm{L}^{-1}$ and the relative standard deviation (R.S.D., $\mathrm{n}=11$ ) was $3.4 \%$ for $20 \mathrm{mg} \mathrm{L}^{-1}$ protocatechuic aldehyde.

Study of interferences: In order to assess the possible analytical application of the proposed chemiluminescence system to samples, The influences of some common inorganic

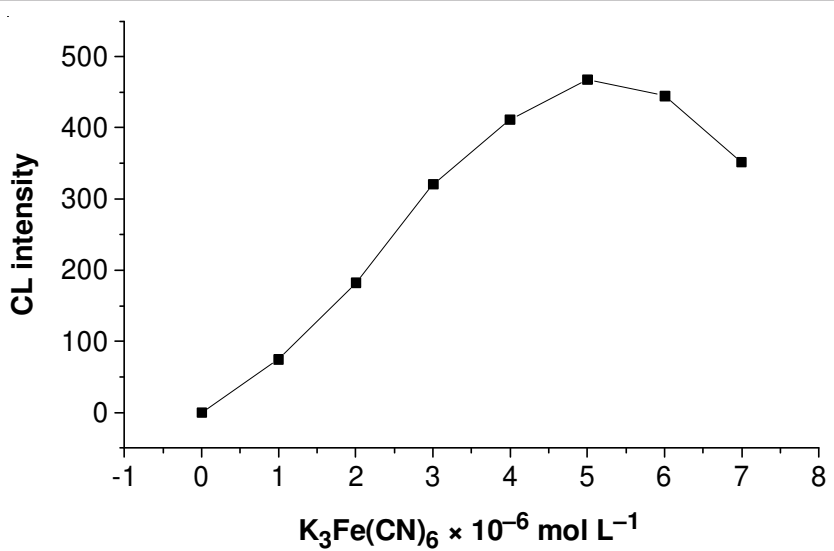

Fig. 5. Effect of $\mathrm{K}_{3}\left[\mathrm{Fe}(\mathrm{CN})_{6}\right]$ concentration on chemiluminescence intensity. Condition: $[\mathrm{PA}]=20 \mathrm{mg} \mathrm{L}^{-1}$, [luminol $]=5.0 \times 10^{-5} \mathrm{~mol}$ $\mathrm{L}^{-1}$, luminol in $0.2 \mathrm{~mol} \mathrm{~L}^{-1} \mathrm{NaOH}$ solution

ions and a couple of relevant organic compounds on chemiluminescence intensities were investigated for measuring 20 $\mathrm{mg} \mathrm{L}^{-1}$ protocatechuic aldehyde. The tolerable concentration ratios with respect to $20 \mathrm{mg} \mathrm{L}^{-1}$ protocatechuic aldehyde standard solution for interference at less than $5 \%$ level were over: 1000 for $\mathrm{K}^{+}, \mathrm{Na}^{+}, \mathrm{Ca}^{2+}, \mathrm{Mg}^{2+}, \mathrm{Fe}^{3+}, \mathrm{Mg}^{2+}, \mathrm{Al}^{3+}, \mathrm{Zn}^{2+} ; 500$ for danshensu (DS-128), L-histidine acid, sodium tartrate, citrate, glucose, fructose; 100 for salviamolic acid B, protocatechuic acid, L-glutamic acid, glycine, respectively.

Sample analysis: The proposed method was applied to the determination of protocatechuic aldehyde in Danshen injection (Sichuan Sunnyhope Pharmaceutical Co. Ltd., No. 100901). $2 \mathrm{~mL}$ Danshen injection diluting to $50 \mathrm{~mL}$ with water and filtered through a $0.45 \mu \mathrm{m}$ membrane filter for the chemiluminescence analysis. The recovery experiment of adding standard had been done at the same time. The determination results were shown in Table-1.

\begin{tabular}{cccccc}
\multicolumn{7}{c}{ TABLE-1 } \\
\multicolumn{7}{c}{$\begin{array}{c}\text { DETERMINATION RESULTS OF PROTOCATECHUIC } \\
\text { ALDEHYDE IN DANSHEN INJECTION }\end{array}$} \\
\hline No. & $\begin{array}{c}\text { Found } \\
\left(\mathrm{mg} \mathrm{L}^{-1}\right)\end{array}$ & $\begin{array}{c}\text { Added } \\
\left(\mathrm{mg} \mathrm{L}^{-1}\right)\end{array}$ & $\begin{array}{c}\text { Total found } \\
\left(\mathrm{mg} \mathrm{L}^{-1}\right)\end{array}$ & $\begin{array}{c}\text { Recovery } \\
(\%)\end{array}$ & $\begin{array}{c}\text { Average } \\
\text { recovery }(\%)\end{array}$ \\
\hline 1 & 304.6 & 300 & 611.2 & 102.2 & \\
2 & 307.1 & 300 & 613.9 & 102.3 & \multirow{2}{*}{103.0} \\
3 & 309.5 & 300 & 619.8 & 103.4 & \\
4 & 310.8 & 300 & 617.9 & 102.4 & \\
5 & 303.4 & 300 & 617.1 & 104.6 & \\
\hline
\end{tabular}

\section{Conclusion}

Protocatechuic aldehyde enhances the chemiluminescence signal of luminol by reaction with $\mathrm{K}_{3}\left[\mathrm{Fe}(\mathrm{CN})_{6}\right]$ in basic media. Based on this, a flow-injection chemiluminescence method for the determination of protocatechuic aldehyde has been developed. The proposed method is sensitive, fast and simple and did not require sophisticated reagents and equipment. This method was used for the determination of protocatechuic aldehyde in Danshen injection with satisfactory results. Furthermore, we believe that the system will have potential analytical applications for determination of protocatechuic aldehyde in other pharmaceutical preparations. 


\section{ACKNOWLEDGEMENTS}

Financial support for this work, in part by a grant from the Key Project of Science and Technology Department of Hebei province (10231016) is gratefully acknowledged.

\section{REFERENCES}

1. L. Zhou, Z. Zuo and M.S. Chow, J. Clin. Pharmacol., 45, 1345 (2005).

2. H.J. Chae, S.W. Chae, D.H. Yun, K.S. Keum, S.K. Yoo and H.R. Kim, Immunopharmacol. Immunotoxicol., 26, 135 (2004).

3. L. Wu, H. Qiao, Y. Li and L. Li, Phytomedicine, 14, 652 (2007).

4. Z. Zhou, Y. Liu, A.D. Miao and S.Q. Wang, Eur. J. Pharmacol., 513, 1 (2005).

5. Z. Zhou, Y. Zhang, X.R. Ding, S.H. Chen, J. Yang, X.J. Wang, G.L. Jia, H.S. Chen, X.C. Bo and S.Q. Wang, Antiviral Res., 74, 59 (2007).
6. J.W. Gao, T. Yamane, H. Maita, S. Ishikawa, S.M. Iguchi-Ariga, X.P. $\mathrm{Pu}$ and H. Ariga, J. Pharmacol. Sci., 115, 36 (2011).

7. H.X. Liu, Y. Liu, J.W. Zhang, W. Li, H.T. Liu and L. Yang, Drug Metab. Dispos., 36, 1562 (2008).

8. L. Zhang, X. G. Xu, Y.Z. Shi, W.H.Shan and B.M.Xu, Chin. J. Pharm. Anal., 17, 253 (1997).

9. Y.L. Pan, L. Zhang and G.N. Chen, Analyst, 126, 1519 (2001).

10. S.N. Zhang, H.L. Yang, Z.Q. Liu, J.P. Liu, W. Li, X.S. Liu and H.B. Qu, Chin. J. Pharm. Anal., 29, 192 (2009).

11. M. Xu, Z.C. Zhang, G. Fu, S.F. Sun, J.H. Sun, M. Yang, A.H. Liu, J. Han and D.A. Guo, J. Chromatogr. B, 856, 100 (2007).

12. J. Xie, Y. Zhang, D. Kong and M. Rexit, J. Food Compos. Anal., 24, 1069 (2011).

13. Chemical Industry Press: Chemiluminescence-basic principles and applications, J.M. Lin, Beijing, pp. 42/16-42/17 (2004). 